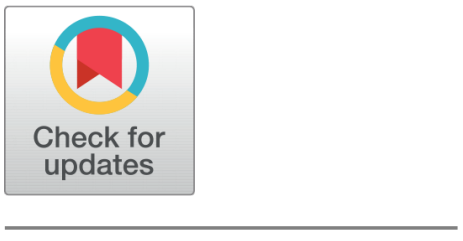

G OPEN ACCESS

Received: 01-04-2020

Accepted: 22-05-2020

Published: 18-06-2020

Editor: Dr. Natarajan Gajendran

Citation: Balaji K, Wessley GJJ (2020) Experimental investigations on the performance of a modified co-flow jet aerofoil. Indian Journal of Science and Technology 13(19): 1873-1881. https://doi.org/ 10.17485/IJST/V13i19.85 *Corresponding author.
G Jims John Wessley

Assistant Professor, Department of Aerospace Engineering, Karunya Institute of Technology and Sciences, Coimbatore, 641 114, Tamil Nadu, India.

Tel.: +91-9487846906

jims_john@karunya.edu

Funding: None

Competing Interests: None

Copyright: (c) 2020 Balaji, Wessley. This is an open access article distributed under the terms of the Creative Commons Attribution License, which permits unrestricted use, distribution, and reproduction in any medium, provided the original author and source are credited.

Published By Indian Society for Education and Environment (iSee)

\section{Experimental investigations on the performance of a modified co-flow jet aerofoil}

\author{
K Balaji ${ }^{1,2}$, G Jims John Wessley ${ }^{3 *}$ \\ 1 Research Scholar, Department of Aerospace Engineering, Karunya Institute of Technology \\ and Sciences, Coimbatore, 641114, Tamil Nadu, India \\ 2 Assistant Professor, Department of Aeronautical Engineering, Sanjay Ghodawat University, \\ Kolhapur, 416118, Maharashtra, India. Tel.: +91-9790115696 \\ 3 Assistant Professor, Department of Aerospace Engineering, Karunya Institute of Technology \\ and Sciences, Coimbatore, 641 114, Tamil Nadu, India. Tel.: +91-9487846906
}

\section{Abstract}

Objectives: To study the performance of a Modified Co Flow Jet (MCFJ) aerofoil with a converging nozzle located at the leading edge so as to reduce the pumping power. Methods: The experimental investigations are conducted on a base aerofoil and a modified CFJ (MCFJ) aerofoil in a subsonic tunnel at various angle of attack (AOA). The output performance parameters like coefficient of Lift $\left(C_{L}\right)$, Coefficient of $\operatorname{drag}\left(C_{D}\right)$ and Lift are obtained for both the aerofoil and the results are compared. Findings: The result shows that the stalling angle of the MCFJ aerofoil advanced by $5^{\circ}$ providing better flow characteristics than the baseline aerofoil. The lift increases up to $43 \%$ during the critical angle of attack of $25^{\circ}$ in the MCFJ aerofoil. Novelty: In the present study, a convergent nozzle is placed near the leading edge of the CFJ aerofoil which effectively controls the mass flow rate of the flow during all phases of flight, thereby resulting in improved aerodynamic performance. Applications: This novel concept can be used for improved aerodynamic performance of MCFJ aerofoil with reduced pumping power. Also, it is possible to obtain improved performance of CFJ Method at all phases of flight by controlling the flow velocity by using the convergent nozzle.

Keywords: Modified co-flow jet; Angle of attack; Coefficient of lift; Coefficient of lift and drag; Aerodynamic performance

\section{Introduction}

During the past few decades there has been an increased interest in improving the performance of the aircrafts by reducing the weight and increasing the aerodynamic performance. One of the most promising approaches to obtain increased aerodynamic performance is the active flow control techniques employed in the wing surfaces to obtain optimum performance in all stages of the flight, cruise efficiency for short take-off and landing possibilities. Co-Flow Jet (CFJ) is a recent technique widely used to increase the performance of the aircraft wing as well as increase the stalling angle of attack. The pertinent problem of boundary layer separation near the leading edge affecting the 
performance of aerofoil is successfully addressed by this flow control method. Here, a particular mass of flow from the trailing edge is drawn into the leading edge of the aerofoil by the help of a pump without disturbing the free stream flow. The suction of a particular mass of flow from the trailing edge and the introduction of the same additional flow in the leading edge portion reduces the wake region and thereby creates more attached flow over the aerofoil which increases the performance of the aerofoil and reduces the drag. However, the CFJ system necessitates the injection hole to be minimum providing a low velocity jet during take-off and landing whereas the injection hole to be larger providing increased flow at the cruise condition of flight which may not be practically possible. This disadvantage is overcome by the introduction of a convergent nozzle to provide the additional flow over the aerofoil. The nozzle flow control is achieved by varying the cross section of the wing during take-off. The wing slat and flap area will be reduced and velocity will be increased to achieve high lift at low angle of attack. At cruise condition, nozzle flow can be maintained constant so that the Airf oil lift to drag ratio (L/D) performance of the aerofoil can be improved drastically throughout the stages of the flight.

In $^{(1)}$ performed experimental test on CFJ and Baseline aerofoil in a subsonic wind tunnel with various Mach number and various angles of attack. This paper shows that the $\mathrm{CFJ}$ aerofoil is seen to improve the lift value and decreases the drag value of a CFJ aerofoil as compared to the baseline aerofoil. $\mathrm{In}^{(2)}$ conduct a practical test on a co-flow jet using Low-speed Wind tunnel using NACA 0015 aerofoil and estimated the aerodynamic performance of baseline and CFJ Aerofoil. This paper concluded that compared to baseline aerofoil the lift generated by the CFJ aerofoil increased by $82.5 \%$ while the drag value reduced by $16.5 \%$. The stall angle of attack was also found to have improved in the CFJ aerofoil. $\operatorname{In}^{(3)}$ investigated the Co-flow jet aerofoil performance in a subsonic wind tunnel with NACA 0015 aerofoil and a modified co-flow model using CFJ0015-065-065 at various angle of attack. This paper confirmed that at various angle of attack the coefficient of pressure values improved. $\operatorname{In}^{(4)}$ conducted an experiment on a new concept called Discrete Co-flow jet (DCFJ). This paper suggested that compared to open co-flow jet method the lift increased by $50 \%$ and drag reduced to $300 \%$ while the stall angle increased by $30 \%$. $\operatorname{In}^{(5)}$ carried out a practical test on DCFJ aerofoil to investigate its aerodynamic performance. This DCFJ aerofoil was investigated with incorporating various stream-wise and span-wise alteration and with various injection hole size. This paper reveals that, the lift was improved by $150 \%$ and the modified aerofoil delayed the generation of the boundary layer over the aerofoil. In ${ }^{(6)}$ conduted windtunnel testing on CFJ aerofoil to estimate the turbulence characterstics over an Aerofoil. It was inferred from the paper that, at low angle of attack, mixing was dominant, whereas, at high angle of attack the presence of turbulence enhanced the mixing of mainflow and additional flow and improved the attached flow. CFJ method is used to improve the coefficient of lift and stalling angle with reduction in coeeficient of drag.

$\mathrm{In}^{(7)}$ carried experimental investigation in a subsonic tunnel to evaluate the aerodynamic performance of CFJ aerofoil. CFJ aerofoil was fabricated with two different injection slot sizes and jet kinetic energy was estimated in a NACA 0025 aerofoil. This paper reveals that the small diameter injection hole increases the lift and stalling angle of attack while the big injection hole decreases the drag in the aerofoil. $\operatorname{In}^{(8)}$ investigated the aerodynamic performance of a CFJ aerofoil in a subsonic wind tunnel with two different injection hole size in a NACA 0025 aerofoil. The results were compared to that of a baseline aerofoil, and it was seen that the aerofoil with small injection hole provided better performance compared to the large hole as well as with the baseline aerofoil. In ${ }^{(9)}$ performed experimental investigation and simulation test on NACA 6415 to find the aerodynamic performance and energy utilized over a CFJ aerofoil. It is seen that after certain angle of attack, shock waves were formed which reduces the performance of aerofoil. It is also seen that, when compared to baseline aerofoil, the lift increased by $120 \%$ in the CFJ aerofoil and also the cruise performance at low angle of attack was better than the baseline aerofoil. $\operatorname{In}^{(10)}$ carried out experimental test of CFJ 6421 aerofoil with a micro compressor in a subsonic wind tunnel. Two different aerofoil were fabricated with different injection slots. Small injection slot was used for takeoff and landing analysis and large injection hole was used for cruise analysis in a CFJ aerofoil. It was reported that CFJ aerofoil achieved super lift coefficient and also suppressed the boundary layer to a great extent and increased the maximum lift coefficient with increase in stall margin.

$\mathrm{In}^{(11)}$ numerically compared the double surface CFJ method with baseline and normal CFJ method in a transonic supercritical RAE2822 aerofoil. It was concluded that for different coefficient of momentum, the $C_{L}$ value of the RAE2822 aerofoil increases compared to other aerofoil. Thus it was established that, the double surface CFJ method improves the performance of aerofoil. In ${ }^{(12)}$ performed numerical analysis on CFJ RAE 2822 transonic aerofoil with constant parameters and varying angle of attack at cruise condition. This study concluded that the aerodynamic performance increased by $14.5 \%$ with a reduction in the energy consumption and it was evident that transonic aerofoil with $\mathrm{CFJ}$ is suitable for cruise conditions at low angle of attack.

The present work aims at increasing the performance of the aerofoil by changing the mass flow rate in a CFJ aerofoil by introducing a convergent nozzle near to the leading edge thereby controlling the flow during cruising and TOL. This system can also be used as a backup during pump failure. 


\section{Experimental Investigations}

\subsection{Fabrication of aerofoil models}

A schematic representation of the baseline aerofoil and the MCFJ aerofoil is shown in [ Figure 1]. NACA 6415 model has been chosen for the present analysis. Baseline aerofoil is fabricated with chord and span size of $25 \mathrm{~cm} \mathrm{x} 25 \mathrm{~cm}$. The top and bottom aerofoil are separately fabricated using wood and pressure tubes are inserted in both the aerofoil.
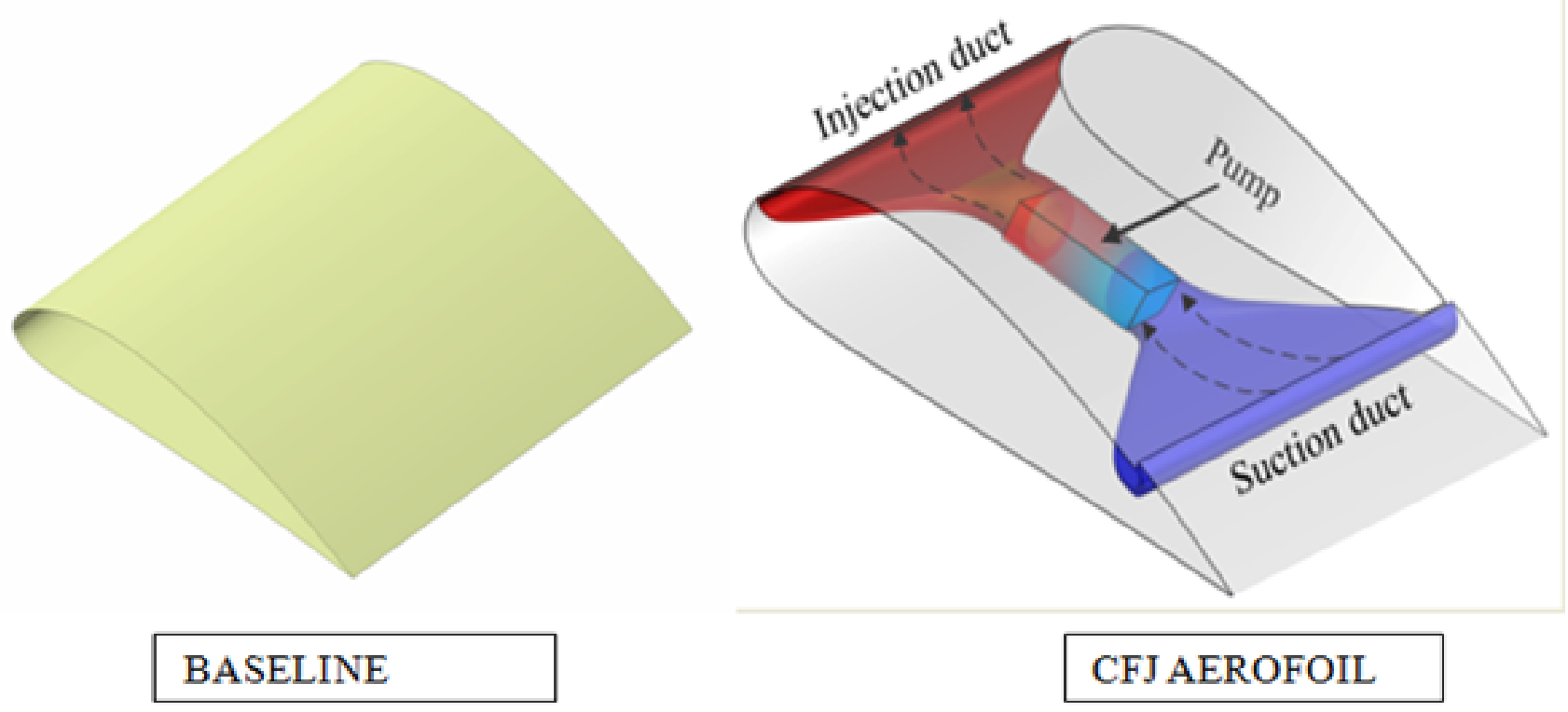

Fig 1. Schematic representation of the baseline and MCFJ aerofoil

Co flow jet models are normally defined by the nomenclature CFJ 4 digit-INJ-SUC. Here the first four digit number is like the normal NACA aerofoil. INJ denotes the leading edge injection slot height to chord length while SUC denotes the suction slot height to chord length. As mentioned, the fabricated aerofoil configuration is seen to be CFJ 6415-065-130 with holes located at $65 \%$ and $130 \%$ of the Chord. It also means that the suction hole is double the time of the injection hole. The injection and suction holes are placed at $7 \%$ and $83.3 \%$ of chord. Nozzle setup is placed near to the leading edge internally which is operated by a separate servo mechanism. The fabricated aerofoil has an overall dimension of span and chord as $25 \mathrm{~cm} \times 25 \mathrm{~cm}$. The models are made up of wood and a nozzle setup is inserted near to the injection point controlled by servo mechanism. The fabricated baseline and MCFJ aerofoil are shown in [ Figure 2].
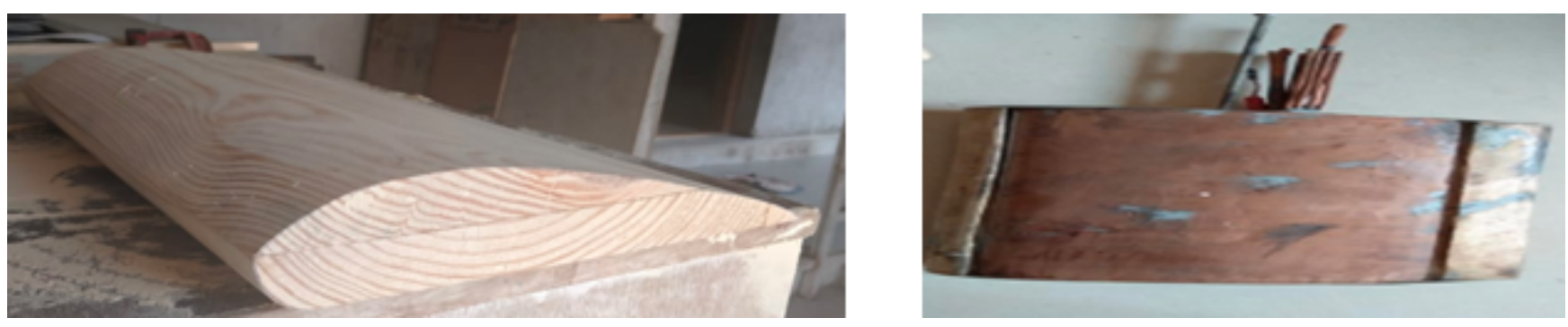

Fig 2. Fabricated baseline NACA 6415 and MCFJ6415-065-130 


\subsection{Wind tunnel test setup}

The subsonic wind tunnel with a test section of $30 \mathrm{~cm} \times 30 \mathrm{~cm}$ that can operate at a maximum velocity of $23 \mathrm{~m} / \mathrm{sec}$ available at the department of Aeronautical Engineering, Annasaheb Dange College of Engineering and Technology, Maharashtra is used for the experimental analysis. Flow is introduced and drawn through the entire span of the Aerofoil. The MCFJ flow is controlled by a modified Vacuum Cleaner that produces a mass flow rate of $0.040 \mathrm{~kg} / \mathrm{sec}$. monitored by gauges. It is ensured that the aerofoil and the MCFJ mechanism does not disturb the operation of wind tunnel. The pictorial representation of the experimental set-up is shown in [ Figure 3].

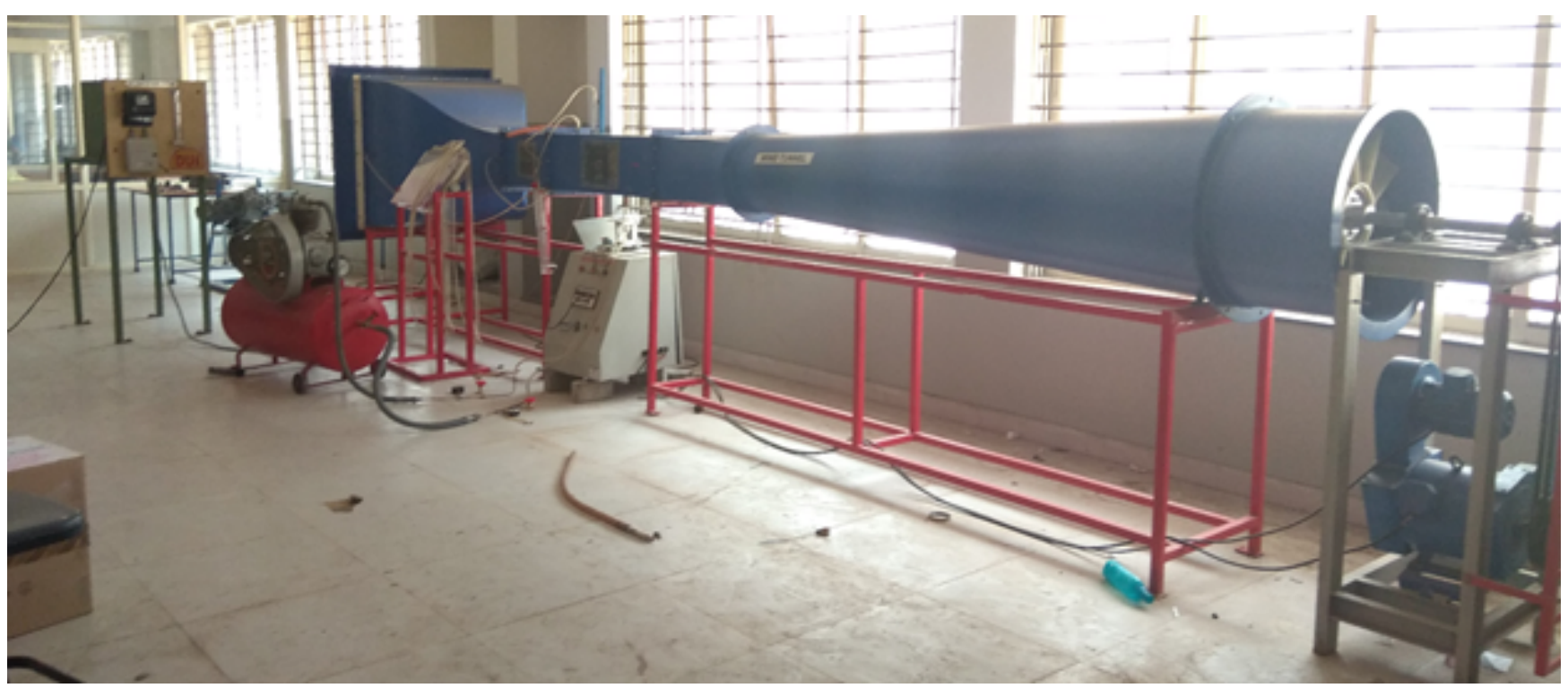

Fig 3. Pictorial representation of the subsonic tunnel used in the present study

The subsonic tunnel is calibrated before conducting the experiments. The results of the calibration is shown in [ Table 1]. The aerodynamic parameters of the baseline and MCFJ aerofoil are obtained at various angle of attacks and the results are obtained.

Table 1. Calibration of subsonic tunnel

\begin{tabular}{llll}
\hline Sl. No & Voltage $(\mathrm{V})$ & Velocity $(\mathrm{m} / \mathrm{s})$ & Mach no \\
\hline 1 & 40 & 9.8 & 0.03 \\
2 & 50 & 13.27 & 0.04 \\
3 & 60 & 16.97 & 0.05 \\
4 & 70 & 23 & 0.07 \\
\hline
\end{tabular}

\section{Results and Discussion}

The baseline and MCFJ aerofoil performances are obtained at various angle of attack and the flow performances are calculated in [ Table 2] 
Table 2. Experimental observations on baseline aerofoil and MCFJ aerofoil

\begin{tabular}{llllllllll}
\hline $\begin{array}{l}\text { Sl. } \\
\text { No. }\end{array}$ & $\begin{array}{l}\text { Angle } \\
\text { Attack }\left(^{\circ}\right)\end{array}$ & of & \multicolumn{3}{c}{ BASELINE AEROFOIL } & & & \multicolumn{2}{c}{ MODIFIED CFJ AEROFOIL } \\
\hline & & CL & Lift & CD & Drag & CL & Lift & CD & Drag \\
1 & 0 & 0.73 & 14.78 & 0.02 & 0.41 & 1.1 & 22.28 & 0.06 & 1.22 \\
2 & 5 & 1.32 & 26.73 & 0.05 & 1.01 & 1.6 & 32.40 & 0.08 & 1.62 \\
3 & 10 & 1.7 & 34.43 & 0.085 & 1.72 & 2.2 & 44.55 & 0.15 & 3.04 \\
4 & 15 & 1.72 & 34.83 & 0.16 & 3.24 & 2.45 & 49.61 & 0.2 & 3.96 \\
5 & 20 & 1.8 & 36.45 & 0.32 & 6.48 & 2.54 & 51.44 & 0.39 & 7.96 \\
6 & 25 & 1.65 & 33.41 & 0.37 & 7.49 & 2.7 & 58.52 & 0.42 & 8.66 \\
7 & 30 & 1.6 & 32.40 & 0.4 & 9.0 & 2.2 & 44.55 & 0.49 & 11.0 \\
\hline
\end{tabular}

\subsection{Comparison of $\mathrm{C}_{L}$ at various angle of attack}

[ Figure 4] shows the variation of coefficient of lift obtained in the baseline aerofoil and MCFJ aerofoil at various angles of attack.

It is seen from the graph that, the coefficient of lift increase in the ange of attack in both the aerofoil under study. It is seen that, the coefficient of lift produdced by the MCFJ is seen to be more than that of the basline aerofoil for all angle of attack. The stalling angle in case of the baseline aerofoil is found as $20^{\circ}$ whereas the stalling of the MCFJ appears at an angle of $25^{\circ}$. This shows the stalling angle has increased by $5^{\circ}$ in $\mathrm{MCFJ}$ and stalling has been delayed due to better aerodynamic performance of MCFJ.

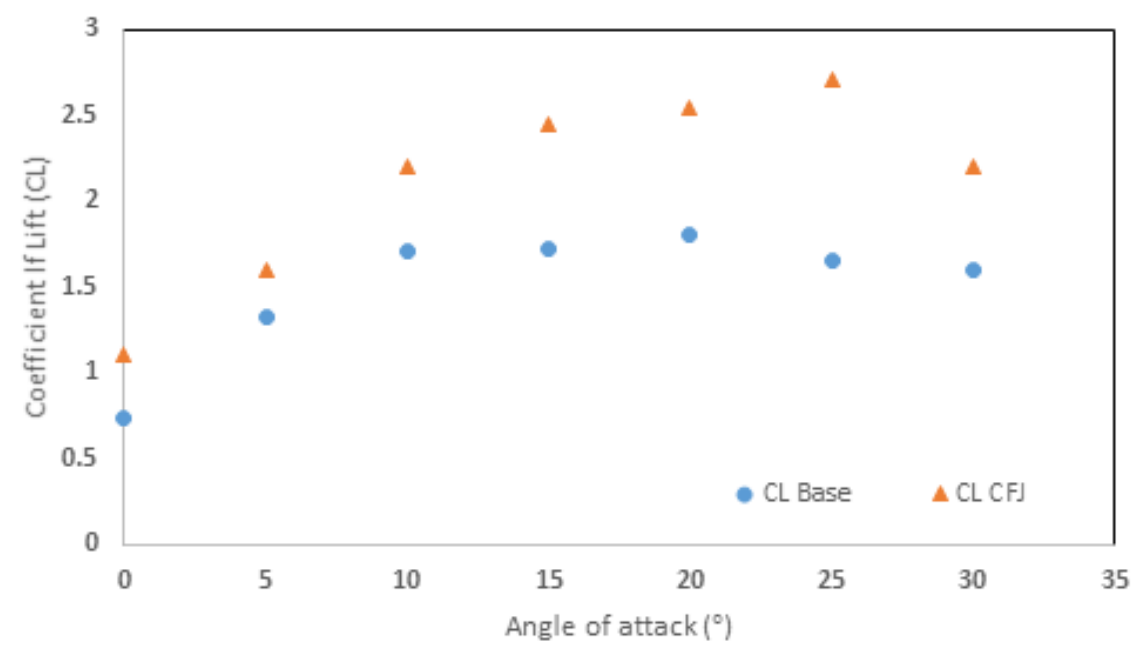

Fig 4. Variation of coefficient of lift $\left(C_{L}\right)$ at various angle of attack

\subsection{Comparison of $\mathrm{C}_{D}$ at various angle of attack}

Figure 5 shows the variation of coefficient of drag obtained in the baseline aerofoil and MCFJ aerofoil at various angles of attack. The graph shows that MCFJ method is creating small increment in drag at low angle of attack compared to baseline aerofoil. The coefficient of drag increases for both the aerofoil at increasing angle of attack. The MCFJ aerofoil shows marginal increase in drag due to increase in lift (lift induced drag). 


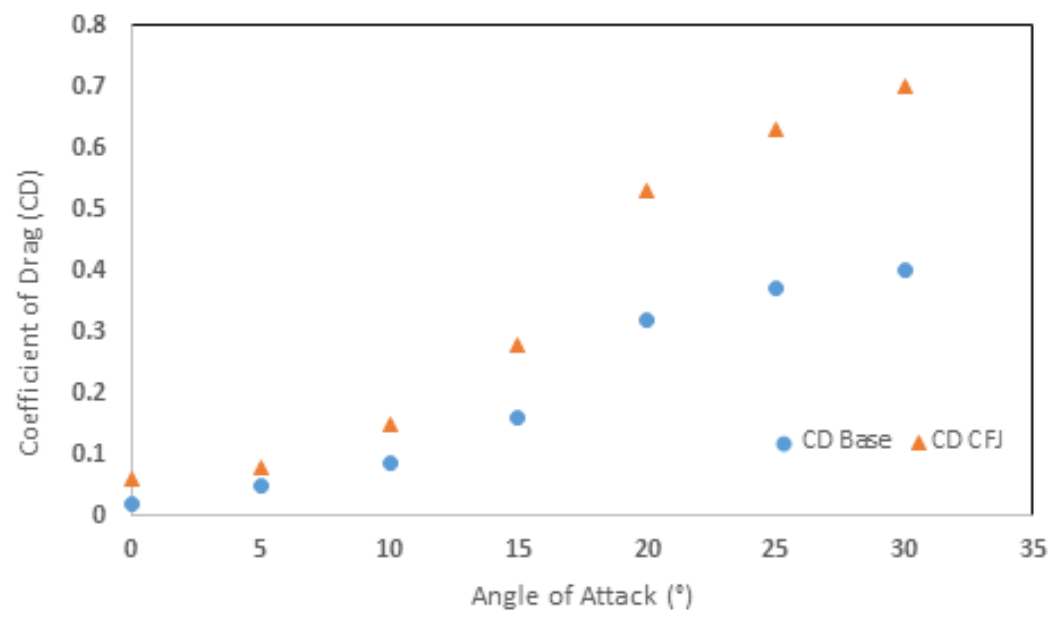

Fig 5. Variation of coeficient of lift $\left(\mathrm{C}_{D}\right)$ at various angle of attack

\subsection{Comparison of $\mathrm{C}_{L} / \mathrm{C}_{D}$ at various angle of attack}

Figure 6 shows the ratio of the coefficent of lift and drag at various angle of attack. It is seen that for low angle of attack MCFJ model is giving average performance.But at higher angle of attack the MCFJ model performs better than the baseline aerofoil.

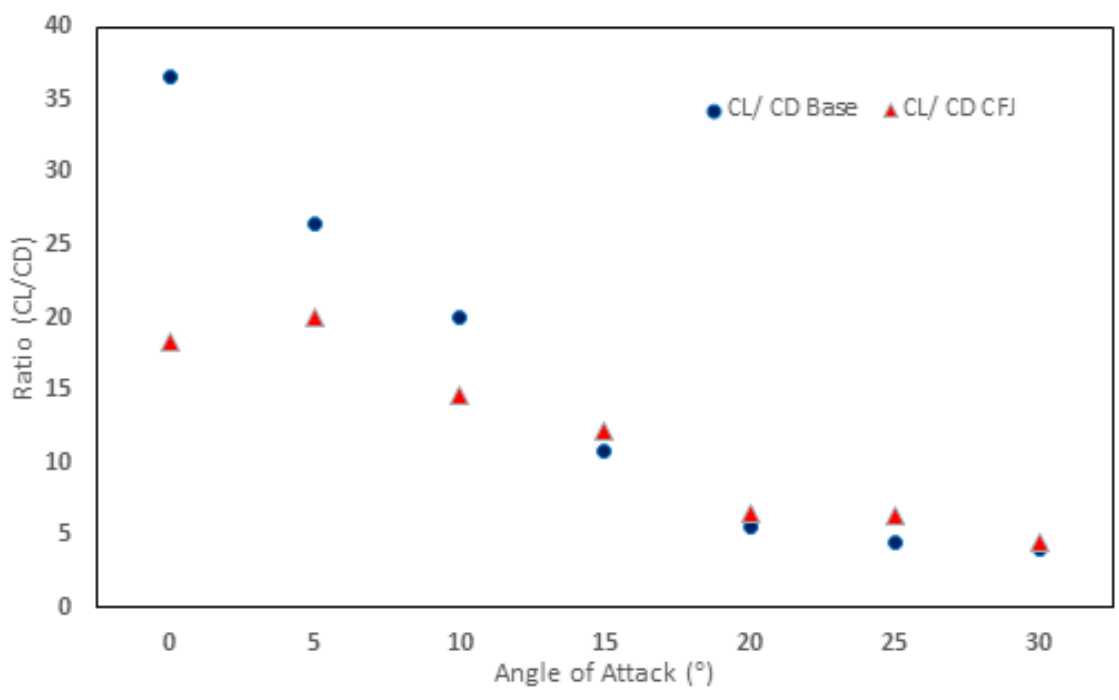

Fig 6. Variation of coefficient of lift and $\operatorname{drag}\left(\mathrm{C}_{L} / \mathrm{C}_{D}\right)$ at various angle of attack

\subsection{Estimation of drag polar}

Figure 7 shows the variation of coefficient of lift and drag of both the aerofoil under study at various angle of attack. The graph shows that the slope of the MCFJ aerofoil is better compared to that of the baseline aerofoil. The improved drag polar denotes improved performance of the aircraft. From the graph, it is concluded that MCFJ wing will result in improved performance of the aircraft. 


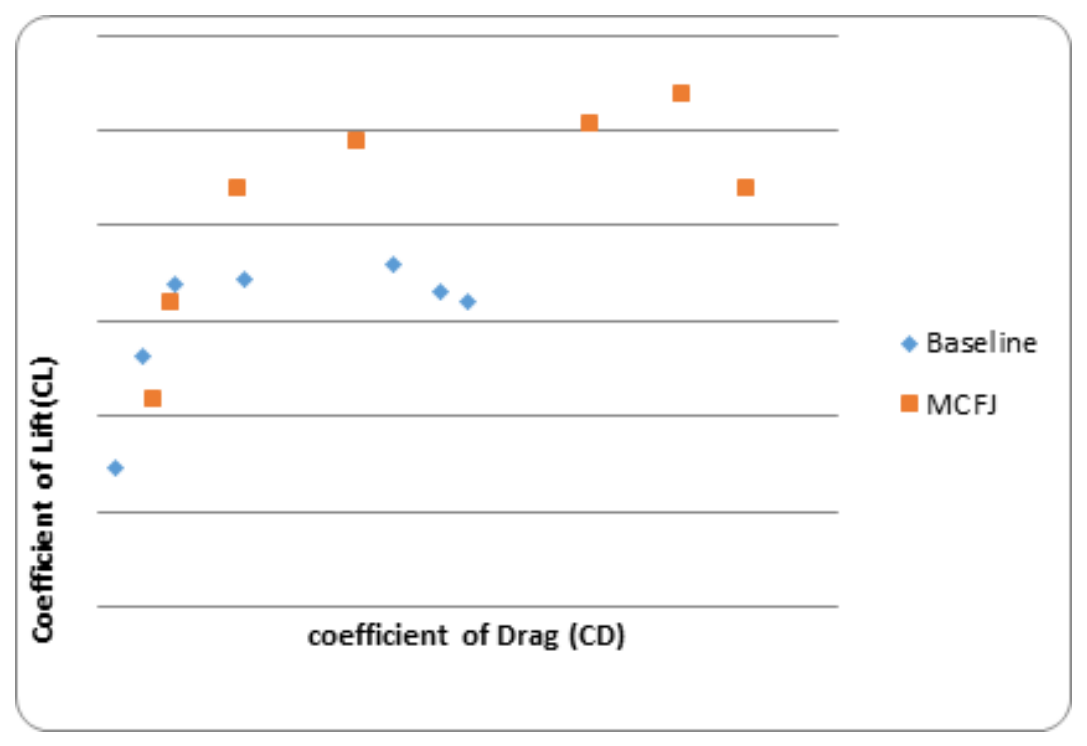

Fig 7. Variation of coefficient of lift $\left(\mathrm{C}_{L}\right)$ and coefficient of drag $\left(\mathrm{C}_{D}\right)$

\subsection{Comparison of Lift generated in baseline and MCFJ aerofoil}

Figure 8 shows the comparision of lift generated by the baseline and MCFJ aerofoil for increasing angle of attack. It is seen that the lift generated by the MCFJ aerofoil is more for all angle attack compared to the baseline aerofoil. It is found that the lift generated varies from $17 \%$ to a maximum of $43 \%$ for various angle of attack. The lift generated by MCFJ at an angle of attack of $25^{\circ}$ is found to be 58.52 as compared to 33.41 with the baseline aerofoil.

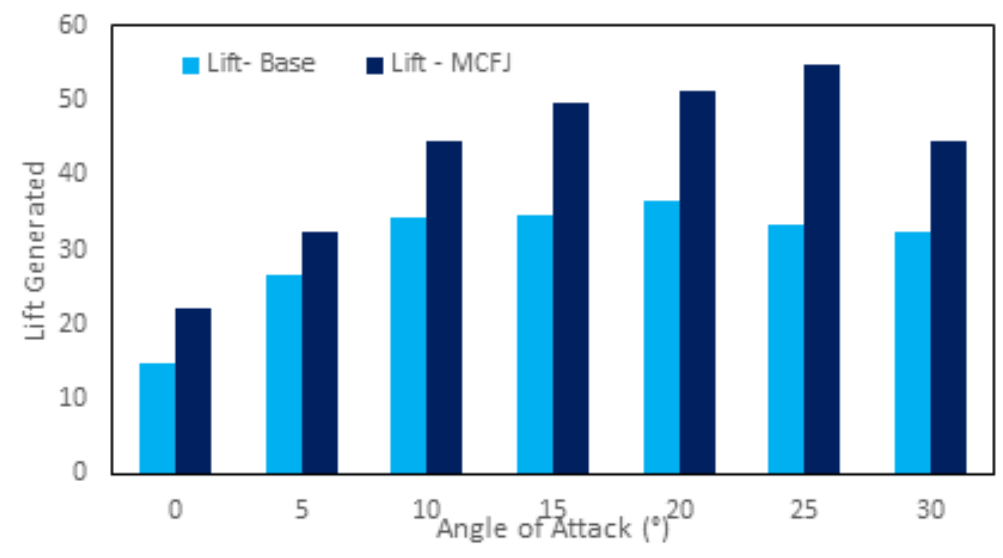

Fig 8. Comparison of Lift generated in aerofoil

\subsection{Comparison of drag generated in baseline and MCFJ aerofoil}

Figure 9 shows the comparison of drag generated by the baseline and MCFJ aerofoil at various angle of attack.

It is evident from the above graph that drag generated by the MCFJ aerofoil is more for all angle attack comapred to the baseline aerofoil. It is found that the drag generated by the MCFJ aerofoil for low angle of attack is high, whereas the increase in drag at high angle of attack is around 15\% compared to the baseline aerofoil. However, the increase in drag during low angle of attack will enable the stability of the aircraft during take-off and landing phases of the flight. 


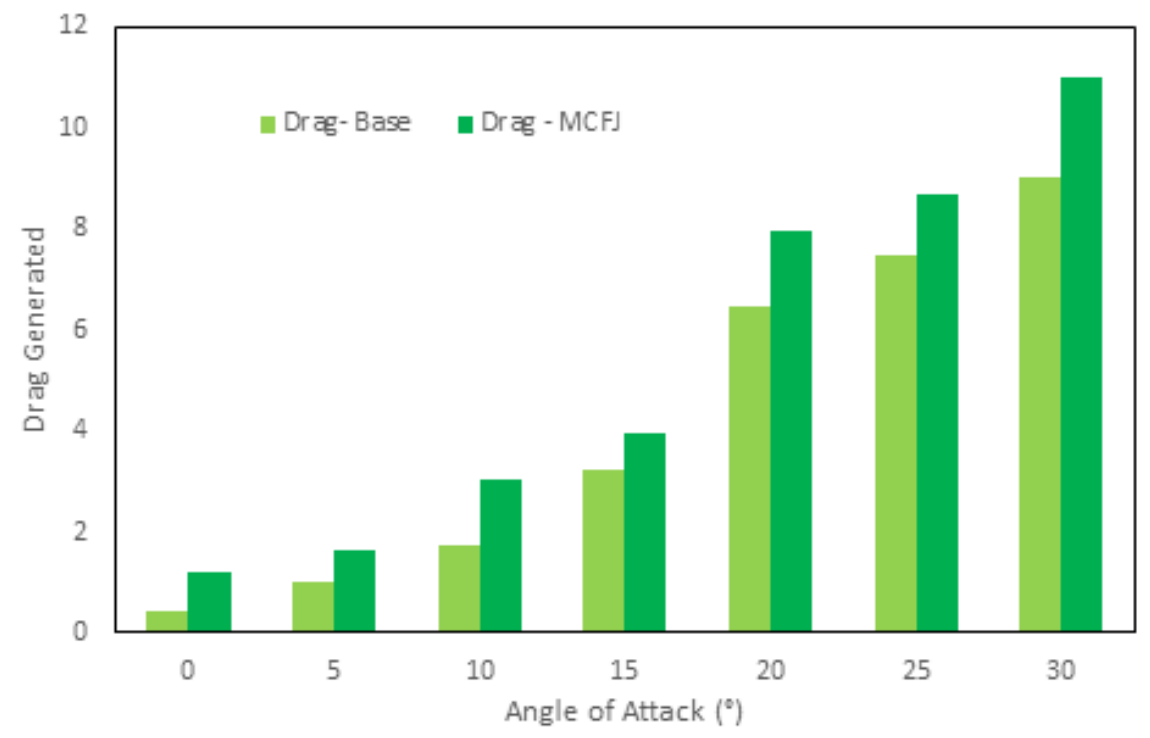

Fig 9. Comparison of Drag generated in aerofoil

\subsection{L/D vs CL performance graph of baseline aerofoil}

The comparison of $\mathrm{L} / \mathrm{D}$ ratio versus $\mathrm{C}_{L}$ in the baseline and MCFJ aerofoil is shown in Figure 10. It is found that CL max value is more compared to the baseline aerofoil which enhances the aerodynamic efficiency of the aerofoil.

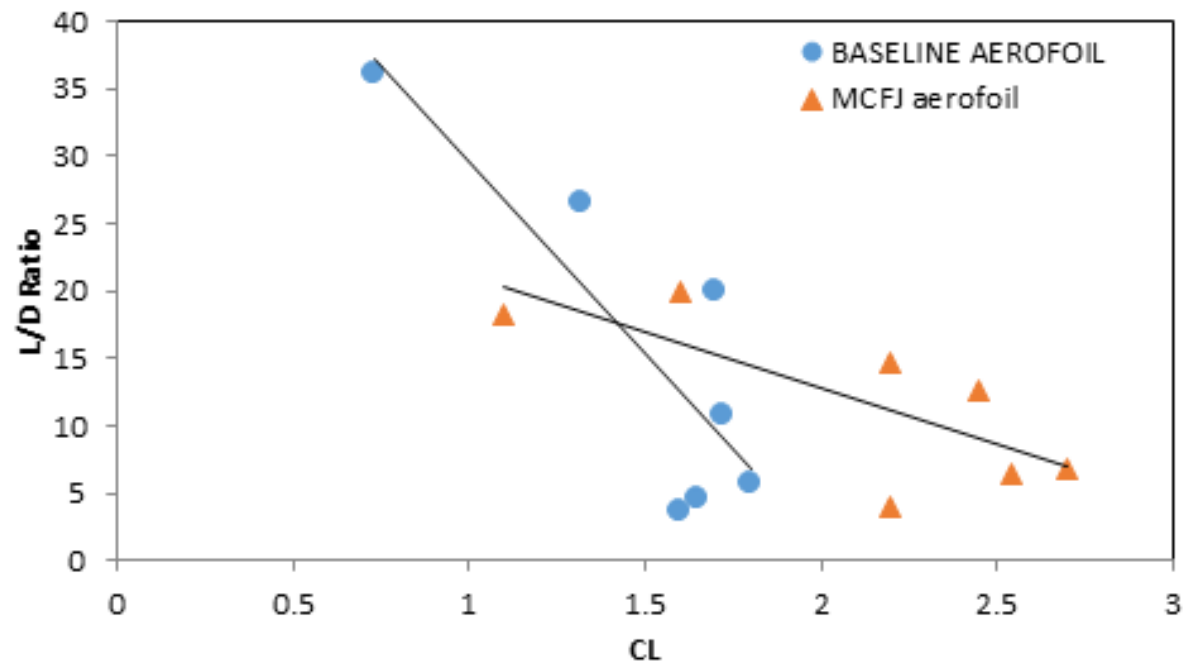

Fig 10. Comparison of $L / D$ ratio at various coefficient of lift in aerofoil

\section{Conclusion}

The aerodynamic performance of the baseline NACA 6415 and the modified aerofoil MCFJ using a nozzle is performed and the following results are obtained:

1. The lift generated by the modified co flow jet aerofoil analyzed in this study yielded more lift in the range of $17 \%$ to $43 \%$ than the baseline aerofoil for various angle of attack considered in this analysis. 
2. The drag produced by the modified co flow jet aerofoil is more (around 60\%) for low angle of attack and is minimum ( $15 \%)$ for higher angle of attack. This increase in drag seen in MCFJ aerofoil improves the stability of the aircraft during low angle of attack operations especially during take-off and landing of the aircraft.

3. It is also seen that the critical angle of attack of the modified co flow jet aerofoil is $25^{\circ}$ and that of the baseline aerofoil is $20^{\circ}$. This shows that the aerodynamic performance of MCFJ aerofoil is improved with more attached flow along the aerofoil and hence can be used for short take off, resulting in economic advantages.

4. It is observed from the results that the $\mathrm{C}_{L M A X}$ value has increased by $50 \%$ and $\mathrm{C}_{D M A X}$ has decreased by $18 \%$, which denotes increased performance of the MCFJ aerofoil compared to the baseline aerofoil.

5. The overall $\mathrm{C}_{L} / \mathrm{C}_{D}$ ratio increment by $46 \%$ compared to that of the baseline aerofoil will increase the aircraft range and endurance.

6. The boundary layer separation is delayed to higher angle of attack so that the power required to operate the systems is reduced.

Hence, it can be concluded that the co flow jet system modified with a nozzle has better flow characteristics which therefore can be implemented in aircrafts for improved aerodynamic performance.

\section{Acknowledgment}

The authors would like to thank the management of Annasaheb Dange College of Engineering and Technology, Maharashtra for providing the necessary experimental facilities to carry out the experimental analysis.

\section{References}

1) Kumar R, Richardson R, Gustavsson J, Cattafesta L, Kumar R. Characterization of RAE 2822 Transonic Airfoil in FSU Polysonic Wind Tunnel Facility. In: AIAA Aerospace Sciences Meeting. 2018. doi:10.2514/6.2018-0328.

2) Hossain MA, Uddin MN, Islam MR, Mashud M. Enhancement of Aerodynamic Properties of an Airfoil by Co Flow Jet. American Journal of Engineering Research. 2015;4(1):103-112.

3) Rajan TEZ, Gowthaman CS, Ganesan, Balaji KMK, Babu. Wind Tunnel Testing of NACA 0021 Aerofoil with Co- Flow Jet. In: and others, editor. International Conference on Systems, Science, Control, Communication, Engineering and Technology. 2015;p. 17-21.

4) Dano PEB, Zha G, Castillo M. Experimental Study of Co-Flow Jet Airfoil Performance Enhancement Using Discrete Jets. In: AIAA 2011-941, 49th AIAA Aerospace Sciences Meeting including the New Horizons Forum and Aerospace Exposition. 2011;p. 4-7. doi:10.2514/6.2011-941.

5) Dano PEB, Lefebvre A, Zha G. Mixing Mechanism of a Discrete Co-Flow Jet Airfoil. In: AIAA 2011-3097, 41st AIAA Fluid Dynamics Conference and Exhibit. 2011;p. 27-30. doi:10.2514/6.2011-3097.

6) Dano BPE, Kirk D, Zha GC. Experimental Investigation of Jet Mixing Mechanism of a Co-Flow Jet Airfoil. In: AIAA 2010-4421, 5th Flow Control Conference. 2010. doi:10.2514/6.2010-4421.

7) Zha GC, Paxton CD, Conley CA, Wells A, Carroll BF. Effect of Injection Slot Size on the Performance of Coflow Jet Airfoil. Journal of Aircraft. 2006;43(4):987-995. doi:10.2514/1.16999.

8) Zha GC, Carroll BF, Paxton CD, Conley CA, Wells A. High Performance Airfoil Using Co-Flow Jet Flow Control. American Institute of Aeronautics and Astronautics. 2005;p. 1-27. doi:10.2514/1.20926.

9) Lefebvre A, Dano B, Bartow WB, Fronzo MD, Zha GC. Performance and Energy Expenditure of Coflow Jet Airfoil with Variation of Mach Number. Journal of Aircraft. 2016;53(6):1757-1767. doi:10.2514/1.c033113.

10) Zha G, Yang Y, Ren Y, Mcbreen B, AIAA AVIATION . Super-Lift and Thrusting Airfoil of Coflow Jet Actuated by Micro-Compressors. In: and others, editor. Flow Control Conference. 2018. Available from: https://doi.org/10.2514/6.2018-3061.

11) Wang L. Investigations of Double Surface Co-Flow Jet Transonic Airfoil. 2019. Available from: https://scholarlyrepository.miami.edu/oa_theses/744.

12) Liu Z, Zha GC. Transonic Airfoil Performance Enhancement Using Co-Flow Jet Active Flow Control" AIAA Paper 2016-3472. In: 8th AIAA Flow Control Conference. 2016. doi:10.2514/6.2016-3472. 